\title{
Attenuated Mismatch Negativity in Attenuated Psychosis Syndrome Predicts Psychosis: Can Galantamine-Memantine Combination Prevent Psychosis?
}

\author{
Maju Mathew Koola \\ Department of Psychiatry and Behavioral Sciences, George Washington University School of Medicine and \\ Health Sciences, Washington, DC, USA
}

\section{Keywords}

Attenuated psychosis syndrome $\cdot$ Clinical high risk .

Galantamine - Memantine - Mismatch negativity · Kynurenic acid $\cdot$ Biomarker

\begin{abstract}
Although first proposed in 1987, early diagnosis and intervention of psychotic disorders has only recently become a priority in the field. The interest in clinical high risk (CHR) for psychosis skyrocketed after attenuated psychosis syndrome (APS) was added to the DSM-5. There is evidence that in individuals with APS, attenuated mismatch negativity (MMN: functioning of the auditory sensory memory system) is a robust biomarker that can predict transition to psychosis. The underlying pathophysiological mechanism of MMN is via the interaction of $\mathrm{N}$-methyl-D-aspartate (NMDA) and alpha-7 nicotinic acetylcholine ( $a-7 n A C h)$ receptors. Galantamine is an acetylcholinesterase inhibitor and a positive allosteric modulator of the $a-7 n A C h$ receptors. Memantine is an NMDA receptor antagonist. Memantine has been shown to enhance MMN in people with schizophrenia. Although no studies with galantamine have measured MMN, encenicline, an a-7 nicotinic partial agonist, increased MMN in people with schizophrenia. MMN has been suggested as a potential
\end{abstract}

biomarker with the galantamine-memantine combination for the treatment of neuropsychiatric disorders. Hence, the galantamine-memantine combination may enhance MMN, thereby preventing $\mathrm{CHR}$ to psychosis. With no treatments available, randomized controlled trials are warranted with the galantamine-memantine combination to delay or prevent conversion to psychosis in individuals with $\mathrm{CHR}$.

ㄷ) 2018 S. Karger AG, Base

A focus on early intervention of psychotic disorders has emerged in the field. Clinical high risk (CHR) for psychosis [1] is diagnosed in individuals who meet at least one of the ultra-high risk inclusion criteria: brief limited intermittent psychotic symptoms, attenuated psychosis syndrome (APS), genetic risk and deterioration syndrome, and basic symptoms [2-4]. APS was added as a category in the DSM5 as a condition for further study [5]. The DSM-5 APS criteria have similar prognostic accuracy as instruments used to assess CHR for psychosis such as the Comprehensive Assessment of at Risk Mental States [6].

Mismatch negativity (MMN) is a neurophysiological response elicited by a sequence of repetitive standard stimuli that is interrupted infrequently by a physically dif-

\section{KARGER}

(C) 2018 S. Karger AG, Basel

E-Mail karger@karger.com

www.karger.com/mnp
Maju Mathew Koola, MD

Department of Psychiatry and Behavioral Sciences

George Washington University School of Medicine and Health Sciences

2300 I St NW, Washington, DC 20037 (USA)

E-Mail majumkoola@gmail.com; mkoola@gwu.edu 
ferent oddball stimulus. The nicotinic [7] and N-methyl-D-aspartate (NMDA) receptors [8] are critical for brain development. The underlying pathophysiological mechanism of MMN is via the interaction of NMDA [9-11] and alpha-7 nicotinic acetylcholine $(\alpha-7 \mathrm{nACh})$ receptors [12-15]. Interneuron function is modulated by $\alpha-7 \mathrm{nACh}$ receptors that are activated by subcortical midbrain cholinergic pathways, which convey sensory gating responses from subcortical mechanisms, and NMDA receptors convey information about unusual or mismatched stimulus characteristics [16].

$\mathrm{MMN}$, an index of a preattentive processing deficit, is reduced in schizophrenia [17]. Deficits in auditory MMN generation in schizophrenia have been replicated extensively since the 1990s. MMN deficits are tied to poor functional outcome $[16,18]$, as recently confirmed in a large cross-sectional study of 1,415 subjects with schizophrenia. In this study, early auditory processing event-related potential (MMN, P300, and reorienting negativity) predicted cognition $(\beta=0.37, p<0.001)$, while cognition itself directly predicted negative symptoms $(\beta=-0.16, p<$ 0.001 ) and indirectly predicted functional outcome [19]. Furthermore, MMN is highly predictive of response to auditory cognitive remediation [20]. MMN was found to be a sensitive and predictive biomarker of perceptual learning during auditory cognitive training in 28 individuals with schizophrenia [21].

In individuals with APS, attenuated MMN amplitude is a robust biomarker [22] that can predict (predictive value of $85 \%$ ) a transition to psychotic disorder/schizophrenia [23]. However, a single time point of MMN to predict transition is unlikely to be the optimal approach [24]. MMN is a translatable brain marker toward early intervention for psychosis [25]. In 25 participants with schizophrenia, 21 first-degree relatives of participants with schizophrenia, and 29 healthy controls, MMN was a stronger predictor of functional outcome than cognition [26]. MMN was significantly reduced in the ultra-high risk group $(n=42,27$ completed the study) and in 6 participants who transitioned to psychosis compared to 29 healthy controls [27]. In a 6-year follow-up study comparing 47 healthy controls and 48 participants with CHR for psychosis, CHR nonremitters had reduced MMN at baseline compared to $\mathrm{CHR}$ remitters and healthy controls. The baseline MMN was the only significant predictor of remission [28].

Galantamine is not only an acetylcholinesterase inhibitor, but also a positive allosteric modulator of the $\alpha_{4} \beta_{2}$ and $\alpha-7 n A C h$ receptors. Memantine is a noncompetitive NMDA receptor antagonist. Galantamine and memantine are US Food and Drug Administration approved for the treatment of Alzheimer's disease (AD). In $\mathrm{AD}$, galantamine $24 \mathrm{mg}$ and memantine $28 \mathrm{mg}$ daily are typically prescribed $[29,30]$. The most common adverse reactions of galantamine $(\geq 5 \%)$ are nausea, vomiting, diarrhea, dizziness, headache, decreased appetite, and decrease in weight [29]. The most common adverse reactions of memantine $(\geq 5$ compared to placebo) are headache, diarrhea, and dizziness [30]. However, these side effects are based on elderly people with dementia. Young adults with CHR may not have these side effects or may be able to tolerate galantamine and memantine better than the elderly. There are no specific contraindications with galantamine and memantine except known hypersensitivity to these medications [29, 30]. Galantamine and memantine are safe medications with no harmful short- or long-term side effects. Therefore, these individuals with CHR seeking help are more likely to remain adherent to "memory- and focus-enhancing medications." Finally, there is no compelling evidence to use antipsychotics to treat APS; in addition, antipsychotics are also associated with safety and ethical concerns.

MMN was enhanced in 13 healthy subjects with memantine $30 \mathrm{mg}$ (Cohen $d=0.87$ ) [31], in rodents with memantine $10 \mathrm{mg} / \mathrm{kg}$ [32], and in 41 people with schizophrenia with memantine $20 \mathrm{mg}$ [33]. No studies with galantamine have measured MMN. However, a randomized controlled trial (RCT) of encenicline (an $\alpha-7$ nicotinic partial agonist) in schizophrenia showed a dose-dependent increase in MMN [34]. Interactive effects of the a-7nACh and NMDA receptors on MMN are well documented $[15,35,36]$. MMN is a potential biomarker with the galantamine-memantine combination for treatment of neuropsychiatric disorders including, but not limited to, schizophrenia. Hence, the galantamine-memantine combination may enhance $\mathrm{MMN}$, thereby preventing CHR to psychosis.

Cognitive and functional impairments are evident during the prodromal period [38]. In 3 meta-analyses comparing level of functioning $(n=3,012)$ and quality of life $(n=945)$, people with CHR had a significant impairment in functioning and worse quality of life than healthy controls [39]. Hence, the galantamine-memantine combination may not only enhance MMN, but also improve other cognitive symptoms and functioning as well. Negative symptoms are prevalent in CHR [40]; the galantamine-memantine combination may also improve these symptoms [37, 41]. In a meta-analysis of RCTs in people with schizophrenia $(n=448)$, memantine was found to have a trend $(p=0.07)$ antipsychotic effect compared to placebo [42]. This antipsychotic effect may be beneficial for transient and subthreshold attenuated psychosis.
72

Mol Neuropsychiatry 2018;4:71-74 DOI: $10.1159 / 000488797$
Koola 
The galantamine-memantine combination may be effective for cognitive impairments in schizophrenia [37, 41, 43-46]. Excess kynurenic acid (KYNA) may be associated with cognitive impairments in schizophrenia [47]. KYNA is an antagonist of the $\alpha-7 n A C h$ and NMDA receptors. The galantamine-memantine combination through the $\alpha-7 \mathrm{nACh}$ and NMDA receptors may counteract the effects of KYNA, thereby improving cognition [37, 41, 43-46]. Although the KYNA hypothesis is well established in schizophrenia [48, 49], there is no evidence of abnormal kynurenine pathway (KP) metabolites in $\mathrm{CHR}$ due to a lack of studies. Future studies are warranted to measure KP metabolites in CHR. KYNA and MMN are brain markers; the field has the opportunity to target both biomarkers concurrently with the galantamine-memantine combination [37] and "nip them in the bud" in people with CHR.

If RCTs are positive in CHR and full-blown schizophrenia, the galantamine-memantine combination may be utilized prodrome through syndrome. This is based on the assumption that not all CHR can be prevented from transitioning to first episode psychosis. Keep in mind that we may not detect all individuals with CHR, and several may have first episode psychosis even without having CHR. With no viable treatments available for individuals with CHR [50], RCTs are warranted with the galantamine-memantine combination to delay or prevent conversion to psychosis and schizophrenia. MMN may be utilized as target engagement to monitor progress with treatment.

\section{Disclosure Statement}

The author declares no conflict of interest.

\section{Funding Sources}

None.

\section{References}

1 Fusar-Poli P: The Clinical High-Risk state for psychosis (CHR-P), Version II. Schizophr Bull 2017;43:44-47.

-2 Fusar-Poli P, Cappucciati M, Borgwardt S, Woods SW, Addington J, Nelson B, Nieman DH, Stahl DR, Rutigliano G, Riecher-Rössler A, Simon AE, Mizuno M, Lee TY, Kwon JS, Lam MM, Perez J, Keri S, Amminger P, Metzler S, Kawohl W, Rössler W, Lee J, Labad J, Ziermans T, An SK, Liu CC, Woodberry KA, Braham A, Corcoran C, McGorry P, Yung AR, McGuire PK: Heterogeneity of psychosis risk within individuals at clinical high risk: a meta-analytical stratification. JAMA Psychiatry 2016;73:113-120.

3 Fusar-Poli P, Cappucciati M, De Micheli A, Rutigliano G, Bonoldi I, Tognin S, RamellaCravaro V, Castagnini A, McGuire P: Diagnostic and prognostic significance of Brief Limited Intermittent Psychotic Symptoms (BLIPS) in individuals at ultra high risk. Schizophr Bull 2017;43:48-56.

-4 Fusar-Poli P, Cappucciati M, Bonoldi I, Hui LM, Rutigliano G, Stahl DR, Borgwardt S, Politi P, Mishara AL, Lawrie SM, Carpenter WT Jr, McGuire PK: Prognosis of brief psychotic episodes: a meta-analysis. JAMA Psychiatry 2016;73:211-220.

$>5$ Tsuang MT, Van Os J, Tandon R, Barch DM, Bustillo J, Gaebel W, Gur RE, Heckers S, Malaspina D, Owen MJ, Schultz S, Carpenter W: Attenuated psychosis syndrome in DSM5. Schizophr Res 2013;150:31-35.
6 Fusar-Poli P, De Micheli A, Cappucciati M, Rutigliano G, Davies C, Ramella-Cravaro V, Oliver D, Bonoldi I, Rocchetti M, Gavaghan L, Patel R, McGuire P: Diagnostic and prognostic significance of DSM-5 attenuated psychosis syndrome in services for individuals at ultra high risk for psychosis. Schizophr Bull 2018;44:264-275.

7 Zheng JQ, Felder M, Connor JA, Poo MM: Turning of nerve growth cones induced by neurotransmitters. Nature 1994;368:140144.

8 du Bois TM, Huang XF: Early brain development disruption from NMDA receptor hypofunction: relevance to schizophrenia. Brain Res Rev 2007;53:260-270.

$\checkmark 9$ Rosburg T, Kreitschmann-Andermahr I: The effects of ketamine on the mismatch negativity (MMN) in humans - a meta-analysis. Clin Neurophysiol 2016;127:1387-1394.

-10 Javitt DC, Steinschneider M, Schroeder CE, Arezzo JC: Role of cortical N-methyl-D-aspartate receptors in auditory sensory memory and mismatch negativity generation: implications for schizophrenia. Proc Natl Acad Sci USA 1996;93:11962-11967.

11 Featherstone RE, Shin R, Kogan JH, Liang Y, Matsumoto M, Siegel SJ: Mice with subtle reduction of NMDA NR1 receptor subunit expression have a selective decrease in mismatch negativity: implications for schizophrenia prodromal population. Neurobiol Dis 2015;73:289-295.
12 Baldeweg T, Wong D, Stephan KE: Nicotinic modulation of human auditory sensory memory: evidence from mismatch negativity potentials. Int J Psychophysiol 2006;59:49-58.

13 Martin LF, Davalos DB, Kisley MA: Nicotine enhances automatic temporal processing as measured by the mismatch negativity waveform. Nicotine Tob Res 2009;11:698-706.

14 Dulude L, Labelle A, Knott VJ: Acute nicotine alteration of sensory memory impairment in smokers with schizophrenia. J Clin Psychopharmacol 2010;30:541-548.

15 Knott V, Shah D, Millar A, McIntosh J, Fisher D, Blais C, Ilivitsky V: Nicotine, auditory sensory memory, and sustained attention in a human ketamine model of schizophrenia: moderating influence of a hallucinatory trait. Front Pharmacol 2012;3:172.

$>16$ Javitt DC, Freedman R: Sensory processing dysfunction in the personal experience and neuronal machinery of schizophrenia. Am J Psychiatry 2015;172:17-31.

17 Shelley AM, Ward PB, Catts SV, Michie PT, Andrews S, McConaghy N: Mismatch negativity: an index of a preattentive processing deficit in schizophrenia. Biol Psychiatry 1991; 30:1059-1062.

18 Kantrowitz JT, Hoptman MJ, Leitman DI, Moreno-Ortega M, Lehrfeld JM, Dias E, Sehatpour P, Laukka P, Silipo G, Javitt DC: Neural substrates of auditory emotion recognition deficits in schizophrenia. J Neurosci 2015;35: 14909-14921. 
19 Thomas ML, Green MF, Hellemann G, Sugar CA, Tarasenko M, Calkins ME, Greenwood TA, Gur RE, Gur RC, Lazzeroni LC, Nuechterlein KH, Radant AD, Seidman LJ, Shiluk AL, Siever LJ, Silverman JM, Sprock J, Stone WS, Swerdlow NR, Tsuang DW, Tsuang MT, Turetsky BI, Braff DL, Light GA: Modeling deficits from early auditory information processing to psychosocial functioning in schizophrenia. JAMA Psychiatry 2017;74:37-46.

-20 Biagianti B, Roach BJ, Fisher M, Loewy R, Ford JM, Vinogradov S, Mathalon DH: Trait aspects of auditory mismatch negativity predict response to auditory training in individuals with early illness schizophrenia. Neuropsychiatr Electrophysiol, in press.

21 Perez VB, Tarasenko M, Miyakoshi M, Pianka ST, Makeig SD, Braff DL, Swerdlow NR, Light GA: Mismatch negativity is a sensitive and predictive biomarker of perceptual learning during auditory cognitive training in schizophrenia. Neuropsychopharmacology 2017;42:2206-2213.

-22 Belger A, Yucel GH, Donkers FC: In search of psychosis biomarkers in high-risk populations: is the mismatch negativity the one we've been waiting for? Biol Psychiatry 2012;71:94-95.

-23 Bodatsch M, Ruhrmann S, Wagner M, Müller R, Schultze-Lutter F, Frommann I, Brinkmeyer J, Gaebel W, Maier W, Klosterkötter J, Brockhaus-Dumke A: Prediction of psychosis by mismatch negativity. Biol Psychiatry 2011; 69:959-966.

-24 Näätänen R, Todd J, Schall U: Mismatch negativity (MMN) as biomarker predicting psychosis in clinically at-risk individuals. Biol Psychol 2016;116:36-40.

25 Nagai T, Tada M, Kirihara K, Araki T, Jinde S, Kasai K: Mismatch negativity as a "translatable" brain marker toward early intervention for psychosis: a review. Front Psychiatry 2013; 4:115.

26 Lee SH, Sung K, Lee KS, Moon E, Kim CG: Mismatch negativity is a stronger indicator of functional outcomes than neurocognition or theory of mind in patients with schizophrenia. Prog Neuropsychopharmacol Biol Psychiatry 2014;48:213-219.

-27 Lavoie S, Jack BN, Griffiths O, Ando A, Amminger P, Couroupis A, Jago A, Markulev C, McGorry PD, Nelson B, Polari A, Yuen HP, Whitford TJ: Impaired mismatch negativity to frequency deviants in individuals at ultrahigh risk for psychosis, and preliminary evidence for further impairment with transition to psychosis. Schizophr Res 2018;191:95-100.

-28 Kim M, Lee TH, Yoon YB, Lee TY, Kwon JS: Predicting remission in subjects at clinical high risk for psychosis using mismatch negativity. Schizophr Bull, in press.
29 Razadyne package insert. Titusville, Janssen Pharmaceuticals, 2013.

30 Namenda package insert. Irvine, Allergan, 2016.

31 Korostenskaja M, Nikulin VV, Kicić D, Nikulina AV, Kähkönen S: Effects of NMDA receptor antagonist memantine on mismatch negativity. Brain Res Bull 2007;72:275-283.

32 Tikhonravov D, Neuvonen T, Pertovaara A, Savioja K, Ruusuvirta T, Näätänen R, Carlson $S$ : Dose-related effects of memantine on a mismatch negativity-like response in anesthetized rats. Neuroscience 2010;167:11751182.

33 Swerdlow NR, Bhakta S, Chou HH, Talledo JA, Balvaneda B, Light GA: Memantine effects on sensorimotor gating and mismatch negativity in patients with chronic psychosis. Neuropsychopharmacology 2016;41:419-430.

34 Preskorn SH, Gawryl M, Dgetluck N, Palfreyman M, Bauer LO, Hilt DC: Normalizing effects of EVP-6124, an a-7 nicotinic partial agonist, on event-related potentials and cognition: a proof of concept, randomized trial in patients with schizophrenia. J Psychiatr Pract 2014;20:12-24.

35 Hamilton HK, D’Souza DC, Ford JM, Roach BJ, Kort NS, Ahn KH, Bhakta S, Ranganathan, $\mathrm{M}$, Mathalon DH: Interactive effects of an Nmethyl-D-aspartate receptor antagonist and a nicotinic acetylcholine receptor agonist on mismatch negativity: implications for schizophrenia. Schizophr Res 2018;191:87-94.

36 Kantrowitz JT: N-methyl-D-aspartate-type glutamate receptor modulators and related medications for the enhancement of auditory system plasticity in schizophrenia. Schizophr Res, in press.

37 Koola MM: Galantamine and memantine combination for cognitive impairments due to electroconvulsive therapy, traumatic brain injury, and neurologic and psychiatric disorders: kynurenic acid and mismatch negativity target engagement. Prim Care Companion CNS Disord 2018;20:17nr02235.

38 Fusar-Poli P, Borgwardt S, Bechdolf A, Addington J, Riecher-Rössler A, Schultze-Lutter F, Keshavan M, Wood S, Ruhrmann S, Seidman LJ, Valmaggia L, Cannon T, Velthorst E, De Haan L, Cornblatt B, Bonoldi I, Birchwood M, McGlashan T, Carpenter W, McGorry P, Klosterkötter J, McGuire P, Yung A: The psychosis high-risk state: a comprehensive state-of-the-art review. JAMA Psychiatry 2013;70:107-120.
39 Fusar-Poli P, Rocchetti M, Sardella A, Avila A, Brandizzi M, Caverzasi E, Politi P, Ruhrmann S, McGuire P: Disorder, not just state of risk: meta-analysis of functioning and quality of life in people at high risk of psychosis. Br J Psychiatry 2015;207:198-206.

40 Devoe DJ, Peterson A, Addington J: Negative symptom interventions in youth at risk of psychosis: a systematic review and network meta-analysis. Schizophr Bull, in press.

41 Koola MM, Sklar J, Davis W, Nikiforuk A, Meissen JK, Sawant-Basak A, Aaronson S, Kozak R: Kynurenine pathway in schizophrenia: galantamine and memantine combination for cognitive impairments. Schizophr Res 2018;193:459-460.

42 Kishi T, Matsuda Y, Iwata N: Memantine add-on to antipsychotic treatment for residual negative and cognitive symptoms of schizophrenia: a meta-analysis. Psychopharmacology (Berl) 2017;234:2113-2125.

43 Koola MM, Buchanan RW, Pillai A, Aitchison KJ, Weinberger DR, Aaronson ST, Dickerson FB: Potential role of the combination of galantamine and memantine to improve cognition in schizophrenia. Schizophr Res 2014; 157:84-89.

44 Koola MM: Kynurenine pathway and cognitive impairments in schizophrenia: pharmacogenetics of galantamine and memantine. Schizophr Res Cogn 2016;4:4-9.

45 Koola MM, Parsaik A: Galantamine-memantine combination effective in dementia: translate to dementia praecox? Schizophr Res Cogn 2018;12:8-10.

46 Koola MM: Galantamine and memantine combination for cognition: enough or more than enough to translate from murines and macaques to men with schizophrenia? Asian J Psychiatry, in press.

47 Wonodi I, Schwarcz R: Cortical kynurenine pathway metabolism: a novel target for cognitive enhancement in schizophrenia. Schizophr Bull 2010;36:211-218.

48 Erhardt S, Schwieler L, Nilsson L, Linderholm $\mathrm{K}$, Engberg G: The kynurenic acid hypothesis of schizophrenia. Physiol Behav 2007;92:203209.

49 Flis M, Szymona K, Morylowska-Topolska J, Urbańska A, Krukow P, Kandefer-Szerszeń M, Zdzisińska B, Urbańska EM, KarakułaJuchnowicz H: The kynurenic acid hypothesis - a new look at etiopathogenesis and treatment of schizophrenia. Pol Merkur Lek 2016; 41:160-164.

-50 Devoe DJ, Farris MS, Townes P, Addington J: Attenuated psychotic symptom interventions in youth at risk of psychosis: a systematic review and meta-analysis. Early Interv Psychiatry DOI: 10.1111/eip.12677. 